\title{
Inner capillary diameter of hypothalamic paraventricular nucleus of female rat increases during lactation
}

\author{
Albertina Cortés-Sol ${ }^{* *}$, Miguel Lara-Garcia ${ }^{1}$, Mayvi Alvarado ${ }^{1}$, Robyn Hudson ${ }^{2}$, Pere Berbel ${ }^{3}$ and Pablo Pacheco ${ }^{1,2}$
}

\begin{abstract}
Background: The role of the endothelial cell (EC) in blood flow regulation within the central nervous system has been little studied. Here, we explored EC participation in morphological changes of the anterior hypothalamic paraventricular nucleus (PVN) microvasculature of female rats at two reproductive stages with different metabolic demand (virginity and lactation). We measured the inner capillary diameter (ICD) of 800 capillaries from either the magnocellular or parvocellular regions. The space occupied by neural (somas, dendrites and axons) and glial, but excluding vascular elements of the neurovascular compartment was also measured in $100-\mu \mathrm{m}^{2}$ sample fields of both PVN subdivisions.

Results: The PVN of both groups of animals showed ICDs that ranged from 3 to 10 microns. The virgin group presented mostly capillaries with small ICD, whereas the lactating females exhibited a significant increment in the percentage of capillaries with larger ICD. The space occupied by the neural and glial elements of the neurovascular compartment did not show changes with lactation.

Conclusions: Our findings suggest that during lactation the microvasculature of the PVN of female rats undergoes dynamic, transitory changes in blood flow as represented by an increment in the ICD through a self-cytoplasmic volume modification reflected by EC changes. A model of this process is proposed.
\end{abstract}

Keywords: Inner capillary diameter, Endothelial cell, Neurovascular compartment, Hypothalamus, Lactation

\section{Background}

The blood brain barrier (BBB) in the central nervous system (CNS) regulates the passage of nutrients, essential components and metabolic constituents between the blood stream and the parenchymal tissue. Although local neural activity is known to promote local blood supply and is the basis of the so-called blood-oxygen level gradient/dependency (BOLD) [1-3], the regulation of local blood flow in the parenchyma of the CNS is not well understood. Contraction of pre-capillary arterioles has been suggested but so far without clear demonstration [4]. Capillaries of the CNS do not have smooth musculature but contractility of pericytes associated with the capillaries of peripheral tissue such as the retina, cardiac and skeletal muscles has been observed [5-9], suggesting

\footnotetext{
* Correspondence: csolb@yahoo.com.mx

${ }^{1}$ Instituto de Neuroetología, Universidad Veracruzana, Dr. Luis Castelazo s/n

Col. Industrial Las Animas, Xalapa, Veracruz 91190, México

Full list of author information is available at the end of the article
}

that contraction of these cells in the CNS can be a mechanism of blood supply regulation [10-12]. However, the finding that pericytes of the CNS lack the $\alpha$-actin protein isoform found in contractile cells [13], appears to exclude their participation in CNS capillary contraction. Angiogenesis described during brain development [14] has also been suggested as a mechanism of blood flow increment, although without clear support in normal adulthood or non-pathological contexts [15-18]. The endothelial cells (EC), pericytes and basal lamina (anatomical constituents of the $\mathrm{BBB}$ ), together with elements of the neurovascular compartment such as neurons, astrocytes, and other glial cells, adapt themselves to maintain homeostasis that promotes tissue survival $[19,20]$. Although the endothelial cell can be considered as an element which plays an important role in blood flow regulation its participation has been little analyzed, at least partly due to the intrinsic difficulty of its individual staining in capillaries of the CNS [21-23]. 
However, in order to better understand the mechanisms that occur during local blood flow changes in the CNS parenchyma, the role of capillary morphology needs to be considered as an important issue. Electron microscopy (EM) has provided knowledge of the capillary wall constituents $[24,25]$, but the small spatial range of this method is a critical and important limitation of this powerful tool, e.g. the size of a capillary endothelial cell is still not known. Despite attempts to obtain markers enabling CNS capillary imaging or visualization of capillary networks through extracellular tracers, fluorescent markers, diamine benzidine reaction, immunocytochemistry as well as brain arterial injection with black ink or venous plastic infusion $[1,15,22-24,26]$, a complete view of the morphology of CNS capillaries still is lacking. In this respect, recently we proposed an alternative histological tool focused on detecting the relative space occupied by the capillary endothelial cell $[27,28]$. This visualization through light microscopy is based on two facts: first, the optical effect that reflecting light produces in fixed and unstained capillaries, and second, evidence provided by EM $[24,25]$ showing that the internal wall of CNS capillaries is exclusively constituted by the endothelial cell. Using this procedure we found that changes in capillary luminal area can be detected indirectly via changes in the inner capillary diameter (ICD).

With the aim of investigating the participation of the capillary endothelial cell in the regulation of blood flow fluctuations that occur in response to changes in neuronal activity, the present study was directed to quantifying the internal diameter of capillaries in the anterior hypothalamic paraventricular nucleus (PVN) in female rats. We chose this nucleus since several of its physiological aspects but not its microvasculature have been intensely studied [29-35]. For example, it is well known that the magno- and parvocellular regions via a neuroendocrine reflex are involved in oxytocin (OT) production and release in response to mammary gland sensory stimulation [36,37], and that the effect varies according to the reproductive phase of the female rat [33-35,37]. Thus, we decided to measure and compare the capillary internal diameter during the diestrous phase of virgin rats and during the lactation period of mother rats. To ensure that the sensory information received by the two groups was significantly different, mammary glands of the mother rats were stimulated by their pups suckling for two weeks of lactation, while virgin rats had no stimulation.

\section{Results}

\section{General microvasculature characteristics}

Unstained brain sections from all animals were characterized by networks of highly interconnected blood vessels with a wide range of calibers (Figure 1). In particular,

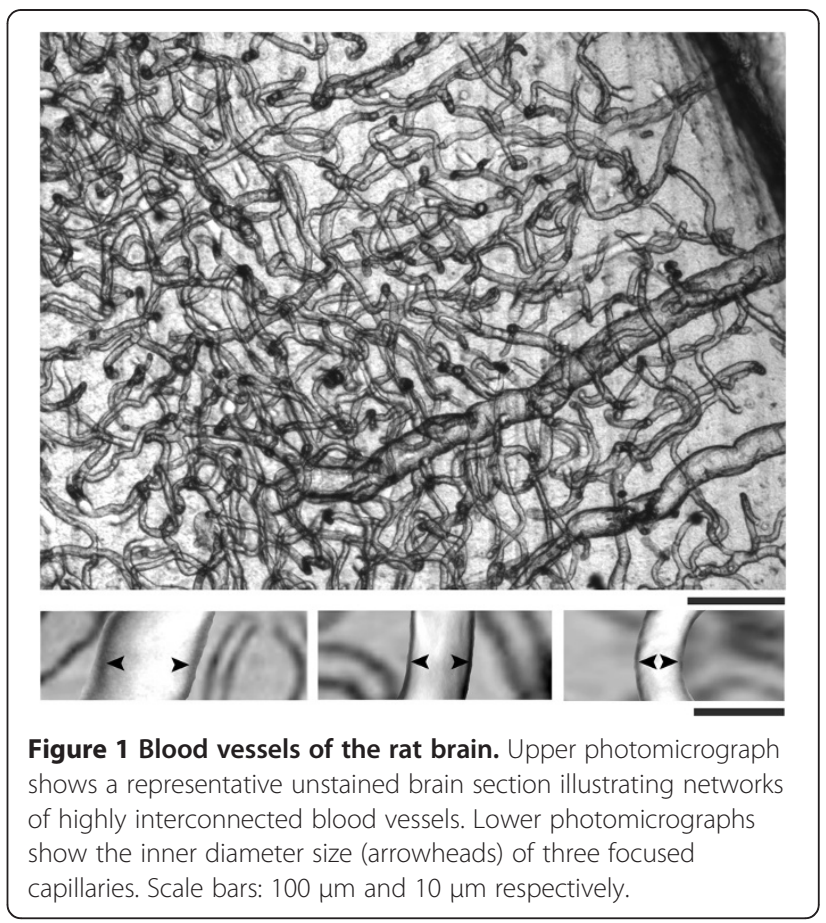

sections from the anterior hypothalamic region showed an area of high capillary density corresponding to the PVN [38]; clearly seen in six serial sections with an anteriorposterior length of approximately $600 \mu \mathrm{m}$ (Figure 2A). This conspicuous density of capillaries could no longer be visualized after cresyl violet staining (Figure 2B), since application of the cover slip and permount modified the optical effect that reflecting light produces on the capillaries, thus impeding their visualization. However, the stained neurons enabled us to confirm the exact PVN location as well as the location of the magno- and parvocellular regions (Figure 3).

\section{Inner capillary diameter (ICD)}

When for the virgin animals in diestrous phase (VIR group) the ICD $(\mu \mathrm{m})$ values from the magnocellular subdivision of the left PVN were compared with those of the right PVN there was no difference $[F(7,64)=1.71$, $\mathrm{P}=0.12]$. Similarly there was no difference when the values from the parvocellular subdivision of the left PVN were compared with those of the right PVN $[F(7,64)=0.88$, $\mathrm{P}=0.52]$. Also in the mother lactating animals (LAC group) the ICD values of the left and right magnocellular subdivisions did not differ $[\mathrm{F}(7,64)=0.14, \mathrm{P}=0.95]$, nor in the left and right parvocellular subdivisions $[\mathrm{F}(7,64)=1.5$, $\mathrm{P}=0.18]$. Therefore, the data from each cellular subdivision were combined. As shown in Figure 4, the VIR group presented ICDs ranging from 3 to $10 \mu \mathrm{m}$ in both regions, with most capillaries located in the $6-\mu \mathrm{m}$ range, followed by the 5 - and $7-\mu \mathrm{m}$ ranges, respectively. When the percentage values of the ICD magnocellular and parvocellular 


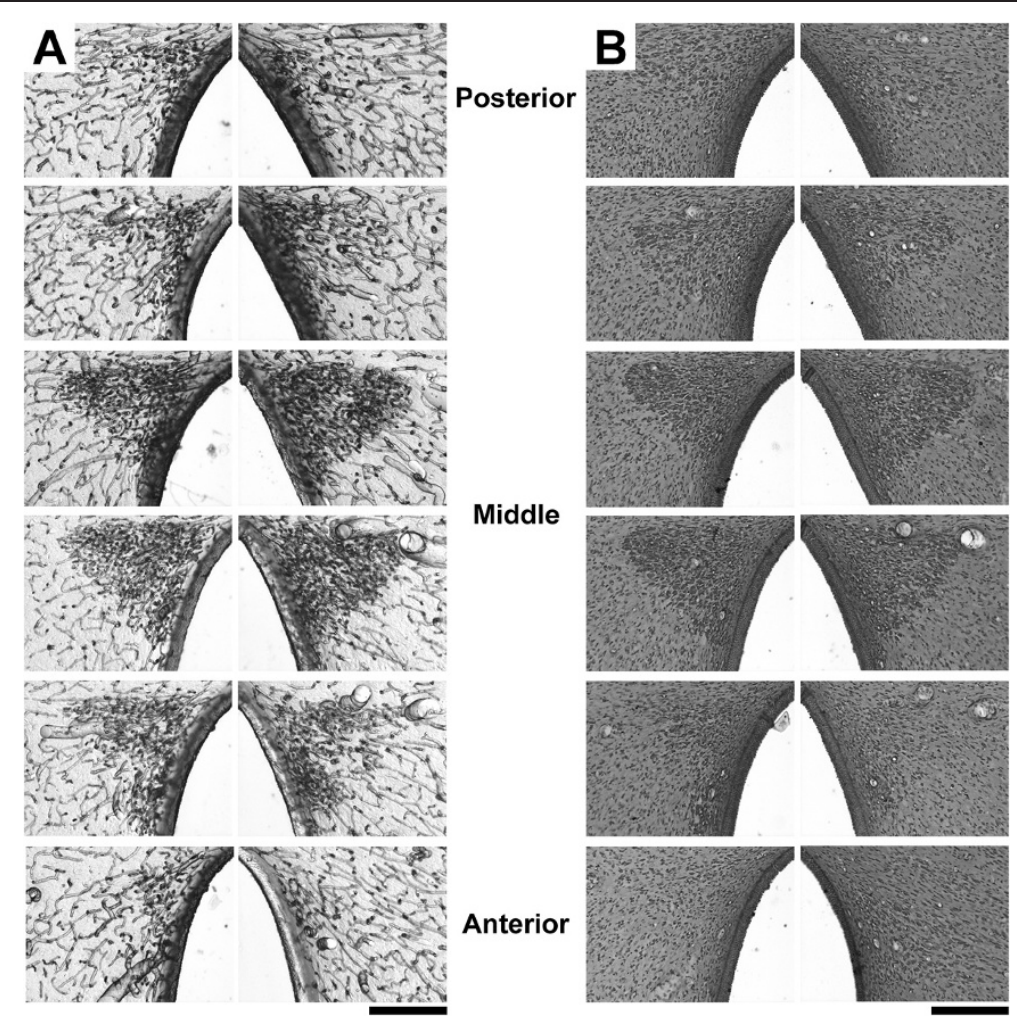

Figure 2 Photomicrographs of transversal sections through the anterior hypothalamus of a female rat. A) High capillary density in the hypothalamic PVN observed in six serial 100- $\mu$ m unstained sections. B) The same six sections after cresyl violet staining; note that capillaries are not visualized but stained neurons can be seen (for details see text). Scale bar: $200 \mu \mathrm{m}$.

subdivisions were compared, they did not differ significantly $[F(7,64)=0.69, P=0.67]$. In contrast, the LAC group showed an ICD distribution that ranged from 4 to $10 \mu \mathrm{m}$ in both regions, with most capillaries located in the $7-\mu \mathrm{m}$ range followed by the 8 - and $6-\mu \mathrm{m}$ ranges, respectively. Again, when the percentage values from the two regions were compared, no difference was found $[F(7,64)=0.34$, $\mathrm{P}=0.93]$. Thus, as seen in Figure 4, the LAC group showed a tendency towards a greater percentage of capillaries with large ICD.

To clarify this observation and since there were no significant differences between the measurements obtained in the two PVN subdivisions of either group, we decided to compare the data between the two experimental conditions by grouping the ICD measurements into two capillary ranges: with small $(3-6 \mu \mathrm{m})$ and large $(7-10 \mu \mathrm{m})$ diameters (Figure 5$)$. This confirmed that the LAC group had a significantly higher percentage of large diameter capillaries compared to the VIR group [One-way ANOVA: $\mathrm{F}(7,32)=23.05,{ }^{*} \mathrm{P}<0.05$ ].

\section{PVN neurovascular compartment}

When values $\left(\mu \mathrm{m}^{2}\right)$ for the space occupied by neural (soma, dendrites and axons) and glial (white area Figure 6), but excluding vascular elements of the neurovascular compartment were compared between PVN magno- and parvocellular subdivisions from the VIR and LAC groups, we found no significant differences between the two groups $[\mathrm{F}(3,16)=2.69, \mathrm{P}=0.08]$; neural and glial elements (white area) occupied approximately $30 \%$ of the space in all the sample fields analyzed.

\section{Discussion}

Whereas the physiology and neuronal characteristics of the PVN have been widely investigated [29-35], its microvasculature has been much less so [29,39,40]. Morphological changes such as glial retraction, neuronal remodeling, c-Fos expression and electrophysiological activity increment during lactation have been reported [35,41-43], and there is no doubt that greater synthesis and release of OT from both the PVN and supraoptic nucleus occurs [33-35]. This could reflect an increment in the local neural activity of these structures that in turn promotes an increment in local blood flow [1-4]. In the present study our results suggest that, at least in the PVN, local blood flow increment could be via an increment in the ICD rather by an increase in outer capillary diameter or angiogenesis. Our findings showing that the area occupied by the neural and glial elements of the neurovascular compartment did not change in virgin 


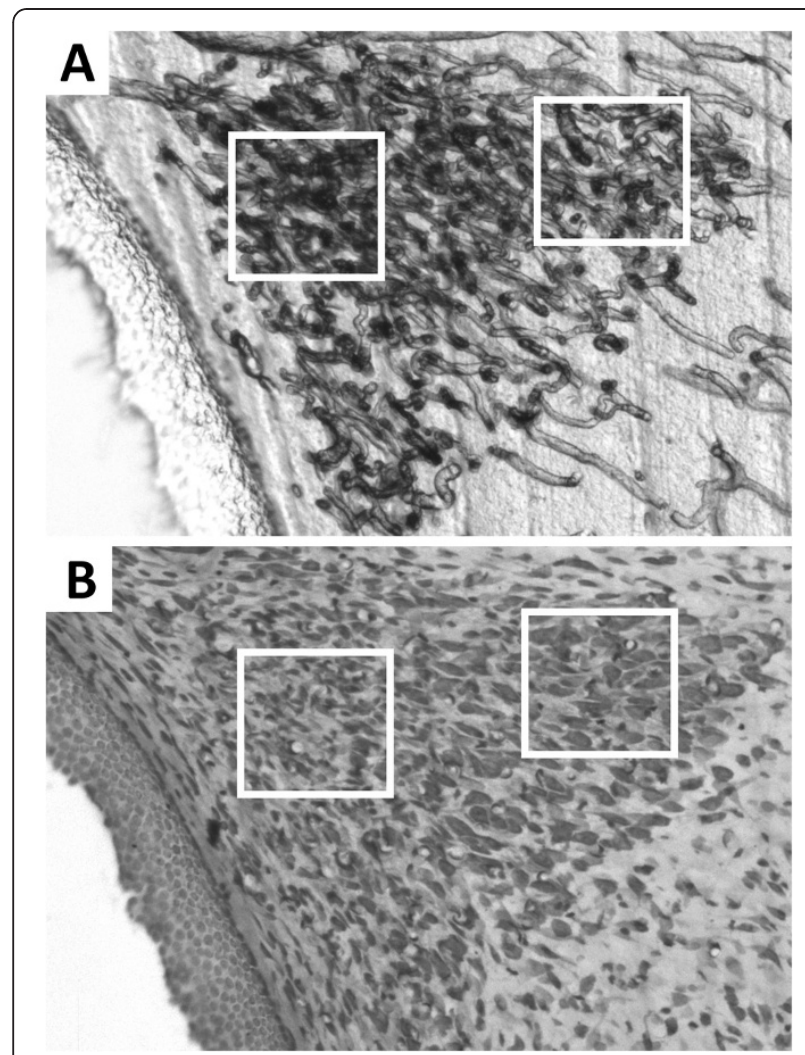

Figure 3 Photomicrograph of a middle transversal section of the PVN from a female rat. A) High capillary density visualized in the still unstained section; note that the border of the nucleus is easily identifiable. B) The same section after cresyl violet staining; capillaries no longer visible but stained neurons can be seen. The $100 \times 100 \mu \mathrm{m}$ squares delimit sampling fields within the parvocellular (left) and magnocellular (right) subdivisions.

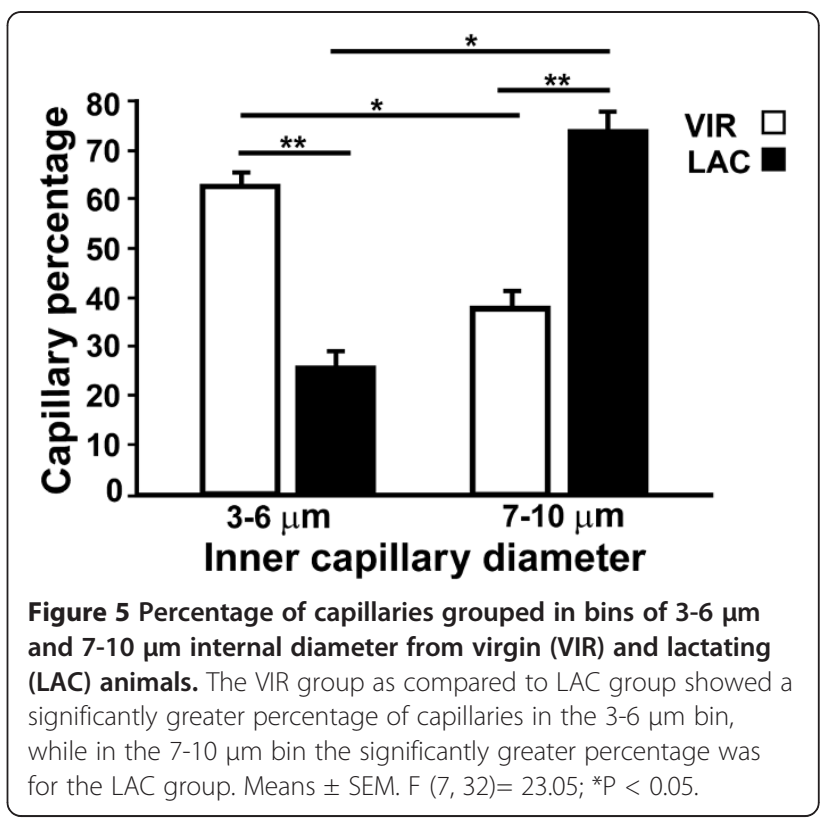

compared to lactating rats, suggest that angiogenesis is not present. In addition, it has been suggested that components of the capillary basal lamina such as laminin, cablin, fibronectin and type IV collagen among others [44-47] prevent the outer EC diameter from expanding.

In relation to our proposal that ICD increment promotes increases in blood flow, we mention the following: Local blood flow regulation in the parenchyma of the CNS is not well understood [4-7,10-12]. However, capillary contraction caused by swelling of EC with no change in the external diameter of the capillary has been previously suggested as an active mechanism of local capillary constriction in peripheral tissue [48]. Thus, in

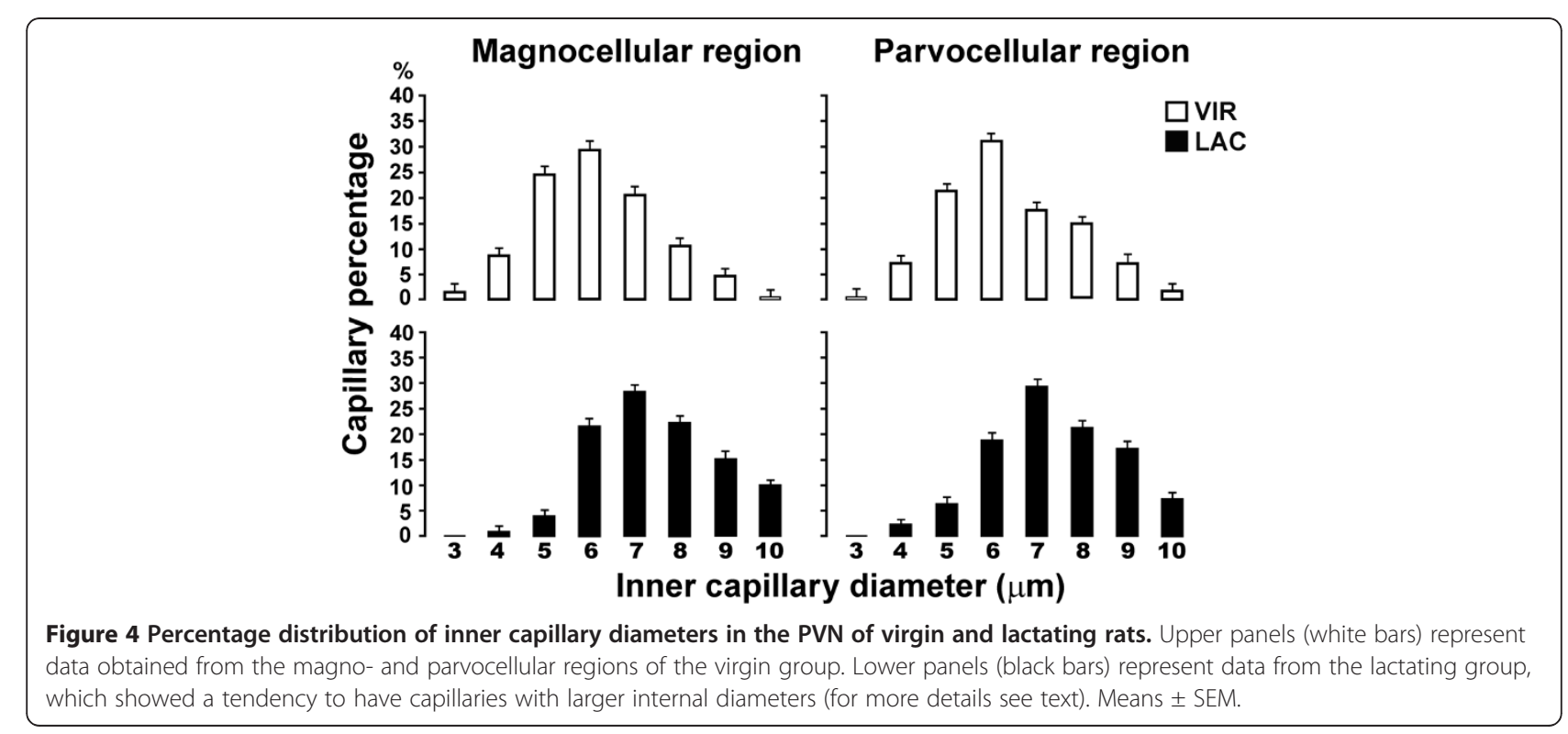




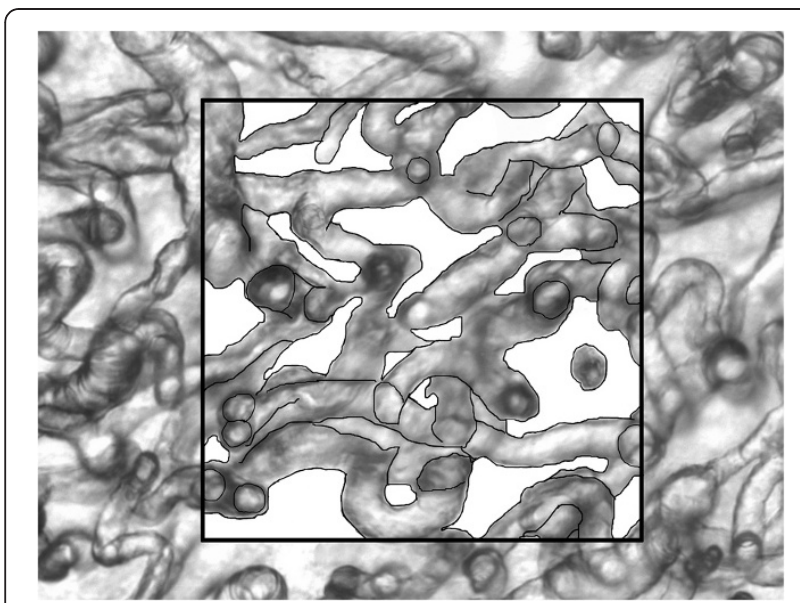

Figure 6 Example of a $100 \times 100-\mu \mathrm{m}$ delimited field from the magnocellular region of the PVN. The white painted area represents the space occupied by neuronal and glial elements of the PVN neurovascular compartment.

accordance with our findings of significant changes in the ICD of PVN microvasculature in the LAC group, we take up this idea again to offer an account of how fast, regional, and reversible control of blood supply in the CNS might occur. Changes in the ICD might take place via modifications of EC cytoplasmic volume; when this decreases the capillary lumen increases (Figure 7A), and the time needed for cytoplasmic transport of substances from the luminal to the abluminal side of the membrane decreases. It is known that the reduction or increase in either local blood supply or the bidirectional "blood $\leftrightarrow$ parenchyma" transport of metabolic constituents depends upon the EC which, together with the basal lamina, constitute the capillary wall $[25,47]$. Accordingly, when the cytoplasmic volume increases, the capillary lumen decreases (Figure 7B), causing cytoplasmic transport of metabolites from the luminal to the abluminal side of the membrane to be slowed. There are a wide variety of factors that modify intracellular osmolarity, thereby promoting changes in cytoplasmic EC volume. Organic osmolytes, taurine, cyclosporine, water, some hormones such as vasopressin (VP) or OT, and free radicals have all been implicated in mechanisms of cell volume regulation [49-53]. Thus, it is possible that neurons and/or astrocytes could modulate their own capillary blood supply as well as the transport and supply of metabolically important substances via such factors.

In addition, it is currently thought that transport of water-soluble molecules across EC is accomplished by the continuous formation of plasmalemma vesicles followed by detachment and fusion to the membrane on the other side of the cell or by transport of cytoplasmic vesicles moving from one surface to the other without

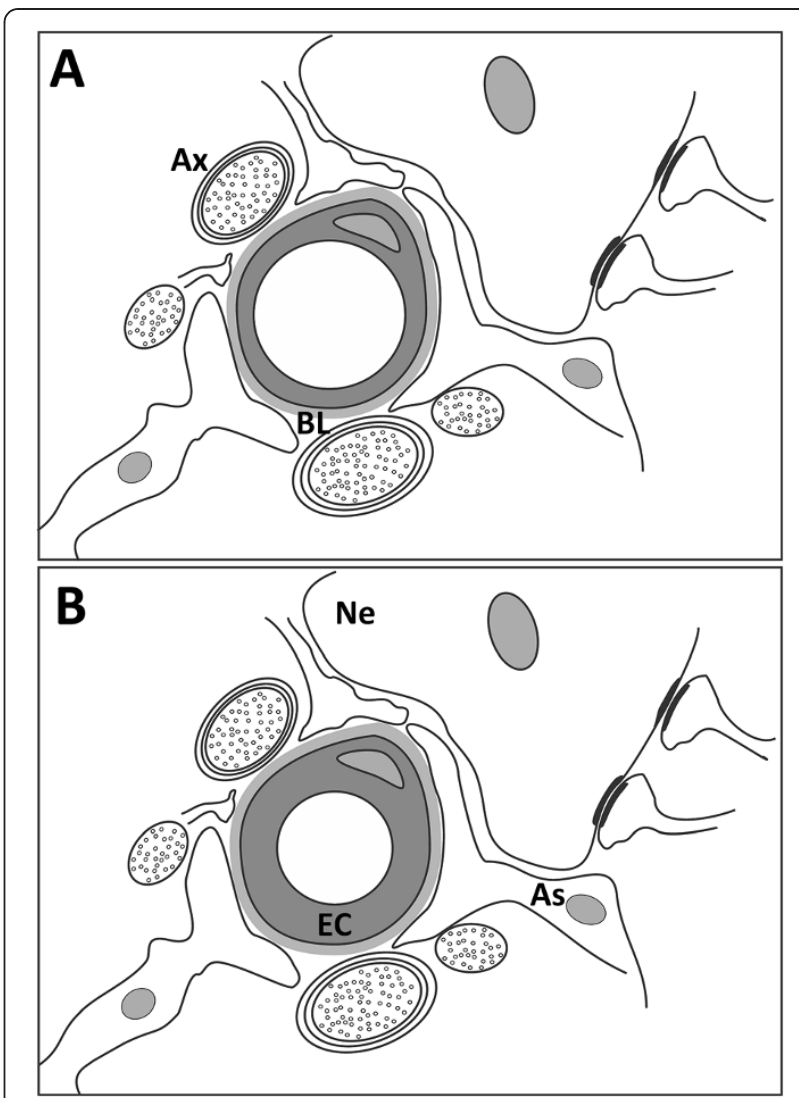

Figure 7 Diagram illustrating our model of the organization of a capillary in the CNS. A) Size of the capillary luminal area when the endothelial cell cytoplasmic volume is reduced. B) The capillary luminal area when the endothelial cell cytoplasmic volume is increased. Note that the outer capillary diameter does not change (for more detail see text). As, astrocyte; Ax, axon; BL, basal lamina; EC, endothelial cell; Ne, neuron.

membrane fusion $[47,54,55]$. Either of these mechanisms of intracellular transport could be present in the capillary $\mathrm{EC}$ and depending on the luminal-abluminal distance the cytoplasmic transport time could be faster or slower. This could represent a dynamic and plastic mechanism by which constantly changing neuronal needs are rapidly met. As physiological changes associated with chronic dehydration, hemorrhage, stress condition as well as pregnancy and parturition [33,56], are associated with the synthesis and release of OT or VP from the PVN and supraoptic nucleus, then, based on our results, we should not reject the idea that a similar dynamic mechanism of blood flow regulation in response to such stimuli might occur.

Finally, it is well-known that during lactation progesterone (P4) and prolactin (PRL) reach high levels in the blood stream [33]. Since PRL has been implicated in OT release $[57,58]$, this hormone could be a potential candidate to participate in PVN blood flow regulation. 


\section{Conclusions}

Our findings suggest that during lactation the microvasculature of the PVN of female rats undergoes dynamic, transitory changes in blood supply represented by an increment in the ICD through self-cytoplasmic volume modification reflected by EC changes. This is relevant to consider from the pharmacological point of view, since changes in cytoplasmic volume in the EC could help to increase blood flow and in this way facilitate the metabolic exchange between capillaries and the CNS parenchyma.

\section{Methods}

\section{Animals, groups, and experimental rationale}

All experimental procedures comply with the requirements of the Institutional Ethical Committee of the Universidad Veracruzana, which is in agreement with the official Mexican regulations (NOM-062-ZOO-1999). In addition the international guidelines for the production, care, and use of laboratory animals from The Society for Neuroscience, USA, were considered.

We used adult female Wistar rats, bred and maintained in the vivarium at the Instituto de Neuroetología, Xalapa, Veracruz. They were kept on a 14:10 light/dark cycle with free access to rat chow (Harlan, Mexico) and water. Given that our aim was to investigate possible changes in the microvasculature of the PVN under different demands for OT secretion, we divided the animals randomly into two groups: virgin females and mother rats. The virgin females were housed in two collective cages $(44 \times 34 \times 20 \mathrm{~cm})$ with 5 animals in each. Their estrous cycle was determinated by vaginal smears and after two regular consecutive estrous cycles, 5 rats were chosen to be perfused during their diestrous-2 phase $(\mathrm{n}=5)$ (VIR group) (they were approximately 140 days old). Mother lactating rats $(\mathrm{n}=5)$ (LAC group) were kept with eight pups each in individual cages $(37 \times 27 \times$ $17 \mathrm{~cm})$. On the $14^{\text {th }}$ day of lactation pups were separated from their mother and maintained in an incubator during $4 \mathrm{~h}$, returned to their mother for a 30-min suckling period, after which the mother was perfused (also when approximately 140 days old). The pups were placed with a nursing dam to minimize animal sacrifice.

\section{Histology}

Under an i.p. overdose of sodium pentobarbital anesthesia $(40 \mathrm{mg} / \mathrm{kg})$, animals were transcardiacally perfused using $50 \mathrm{ml}$ of a $0.9 \%$ saline solution and $300 \mathrm{ml}$ of fixative at $4{ }^{\circ} \mathrm{C}$ ( $4 \%$ paraformaldehyde, $1 \%$ glutaraldehyde, $0.002 \%$ calcium chloride and $3.2 \%$ sucrose, diluted in $0.1 \mathrm{M}$ phosphate buffer $\mathrm{pH}$ 7.4). To minimize the effects of anoxic conditions and perfusion pressure on vessel diameters, the perfusion procedure was standardized in all animals (Masterflex pump 77200, 100 strokes-min, $0.25 \mathrm{ml} /$ stroke calibration). Brains were rapidly removed into fresh fixative for $12 \mathrm{hr}$. They were then mounted on a vibratome (EMS OTS-4000) and $100-\mu \mathrm{m}$ serial transversal sections were cut. Sections at the anterior hypothalamus level [38] were collected in $0.1 \mathrm{M}$ phosphate buffer, mounted on gelatinized slides and dried at room temperature for immediate microscopy analysis (sections remained unstained) (Figures $2 \mathrm{~A}$ and $3 \mathrm{~A}$ ). Afterwards, sections were stained using the Nissl technique (0.04\% cresyl violet, $\mathrm{pH} 3.4)$ and prepared with a cover slip and permount for histological confirmation of the PVN borders as well as for identification of the magnoand parvocellular regions (Figure 3B).

\section{Inner capillary diameter (ICD)}

The unstained sections were examined at 20X and $40 \mathrm{X}$ magnification under a light microscope (Olympus CX31) equipped with a video camera (CoolSNAP-Pro, MediaCybernetics, Inc) for image storage. The condenser lenses were aligned to assure that Koehler illumination was optimal. Measurements were made using Image-Pro plus v.6 software (MediaCybernetics, Inc). The capillaries were clearly visualized, as well as their ICD (Figure 1 lower panel). When the ICD was larger than $10 \mu \mathrm{m}$, we considered it as a vessel instead of a capillary [59] and excluded it from our analysis. In the sections corresponding to the PVN middle area (see Figure 3), 20 capillaries from each magno- and each parvocellular subdivision from both sides were randomly selected and focused to measure their ICDs. A total of 80 measurements per animal were obtained and thus 400 measurements for each group.

Considering the criteria used in other studies where a morphometric analysis was done $[60,61]$ the percentage distribution of capillaries was organized according to individual ICDs for each PVN region (magno- or parvocellular) and for each group of rats. Also, in the present work the mean ICD percentage distribution was calculated and categorized according to bins, with an ICD range of 3-6 and 7-10 $\mu \mathrm{m}$ each.

\section{PVN neurovascular compartment}

After the analysis of ICDs, the area occupied by the neural and glial elements of the PVN neurovascular compartment in the magno- and parvocellular regions within each group (10 fields per group) was measured in a field of $10,000 \mu \mathrm{m}^{2}$ by painting them out so as to exclude the intravascular space (Figure 6).

\section{Statistical analysis}

The percentage of PVN capillaries distributed according to the ICD size and the space occupied by neural and glial elements of the neurovascular compartment were both analyzed using a one-way ANOVA. Tukey's HSD 
post-hoc test was applied when necessary and statistical significance set at $\mathrm{P}<0.05$. Data were analyzed using SPSS Statistics v.18 software (IBM). Descriptive statistics are expressed as means \pm SEM.

\section{Abbreviations}

BBB: Blood brain barrier; CNS: Central nervous system; EC: Endothelial cell; EM: Electron microscopy; ICD: Inner capillary diameter; LAC: Lactating group; OT: Oxytocin; PRL: Prolactin; PVN: Hypothalamic paraventricular nucleus; VIR: Virgin group; VP: Vasopressin.

\section{Competing interest}

The authors declare that they have no competing interests.

\section{Authors' contributions}

ACS participated in the design of the study, performed the experiment, processed and analyzed the data, and drafted the manuscript. MLG provided assistance with data processing and analyses. MA provided recommendations for the experimental design and analyses. RH and PB provided insight, recommendations and edited the manuscript. PP conceived the study, supervised the experimental design and the coordination of all parties involved with the study, and edited the manuscript. All authors read and approved the final draft.

\section{Acknowledgments}

We gratefully acknowledge Dr. Hans Distel (Institut für Medizinische Psychologie Ludwig-Maximilians-Universität München Goethestr. 3180336 München, Germany), for his critical comments and thank Carolina Rojas for technical assistance. This work was supported by Spanish grant from the "Ministerio de Ciencia e Innovacion" SAF2009-10689 to PB and by a CONACyT (México) fellowship to ACS 201991.

\section{Author details}

'Instituto de Neuroetología, Universidad Veracruzana, Dr. Luis Castelazo s/n Col. Industrial Las Animas, Xalapa, Veracruz 91190, México. ${ }^{2}$ Instituto de Investigaciones Biomédicas, Universidad Nacional Autónoma de México, Ciudad Universitaria, México D.F 04510, México. ${ }^{3}$ Departamento de Histología y Anatomía, Facultad de Medicina, Universidad Miquel Hernández, Crta. Nacional, Km-332 s/n, Sant Joan, Alicante 03550, España.

Received: 15 August 2012 Accepted: 8 January 2013

Published: 10 January 2013

\section{References}

1. Villringer A, Dirnagl U: Coupling of brain activity and cerebral blood flow: basis of functional neuroimaging. Cerebrovasc Brain Metab Rev 1995, 7:240-276.

2. Thompson JK, Peterson MR, Freeman RD: Single-neuron activity and tissue oxygenation in the cerebral cortex. Science 2003, 299:1070-1071.

3. Pillai JJ: Insights into adult postlesional language cortical plasticity provided by cerebral blood oxygen level-dependent functional MR imaging. AJNR Am J Neuroradiol 2010, 31:990-996.

4. Malonek D, Dirnagl U, Lindauer U, Yamada K, Kanno I, Grinvald A: Vascular imprints of neuronal activity: relationships between the dynamics of cortical blood flow, oxygenation, and volume changes following sensory stimulation. Proc Natl Acad Sci USA 1997, 94:14826-14831.

5. Herman IM, D'Amore PA: Microvascular pericytes contain muscle and non-muscle actins. J Cell Biol 1985, 101:43-52

6. Tilton RG: Capillary pericytes: perspectives and future trends. J Electron Microsc Tech 1991, 19:327-344.

7. Metea MR, Newman EA: Glial cells dilate and constrict blood vessels: a mechanism of neurovascular coupling. J Neurosci 2006, 26:2862-2870.

8. Peppiatt CM, Howarth C, Mobbs P, Attwell D: Bidirectional control of CNS capillary diameter by pericytes. Nature 2006, 443:700-704.

9. Fernández-Klett F, Offenhauser N, Dirnagl U, Priller J, Lindauer U: Pericytes in capillaries are contractile in vivo, but arterioles mediate functional hyperemia in the mouse brain. Proc Natl Acad Sci USA 2010, 107:22290-22295.
10. Hamilton NB, Attwell D, Hall CN: Pericyte-mediated regulation of capillary diameter: a component of neurovascular coupling in health and disease. Front Neuroenergetics 2010, 2:5-18.

11. Bonkowski D, Katyshev V, Balanov RD, Borisov A, Dore-Duffy P: The CNS microvascular pericyte: pericyte-astrocyte crosstalk in the regulation of tissue survival. Fluids Barriers CNS 2011, 8:8.

12. Dalkara T, Gursoy-Ozdemir Y, Yemisci M: Brain microvascular pericytes in health and disease. Acta Neuropathol 2011, 122:1-9.

13. Nehls $V$, Drenckhahn D: Heterogeneity of microvascular pericytes for smooth muscle type alpha-actin. J Cell Biol 1991, 113:147-154.

14. Argandoña $E G$, Lafuente JV: Effects of dark-rearing on the vascularization of the developmental rat visual cortex. Brain Res 1996, 732:43-51.

15. Black JE, Issacs KR, Anderson BJ, Alcantara AA, Greenough WT: Learning causes synaptogenesis whereas motor activity causes angiogenesis, in cerebellar cortex of adult rats. Proc Natl Acad Sci USA 1990, 87:5568-5572.

16. LaManna JC, Chavez JC, Pichiule P: Structural and functional adaptation to hypoxia in the rat brain. J Exp Biol 2004, 207:3163-3169.

17. Alonso G, Galibert E, Duvoid-Guillou A, Vincent A: Hyperosmotic stimulus induces reversible angiogenesis within the hypothalamic magnocellular nuclei of the adult rat: a potential role for neuronal vascular endothelial growth factor. BMC Neurosci 2005, 24:6-20.

18. Weber B, Keller AL, Reichold J, Logothetis NK: The microvascular system of the striate and extrastriate visual cortex of the macaque. Cereb Cortex 2008, 18:2318-2330.

19. Balabanov R, Dore-Duffy P: Role of the CNS microvascular pericyte in the blood-brain barrier. J Neurosci Res 1998, 53:637-644.

20. del Zoppo GJ: The neurovascular unit in the setting of stroke. J Intern Med 2010, 267:156-171.

21. Bell MA, Scarrow WG: Staining for microvascular alkaline phosphatase in thick celloidin sections of nervous tissue: morphometric and pathological application. Microvasc Res 1984, 27:189-203.

22. Harrison R, Harel N, Panesar J, Mount R: Blood capillary distribution correlates with hemodynamic-based functional imaging in cerebral cortex. Cereb Cortex 2002, 12:125-233.

23. Chilingaryan A, Chilingaryan AM, Martin GG: The three-dimensional direction of microvasculature bed in the brain of white Rattus norvergicus by a $\mathrm{Ca}^{2+}$-ATPase method. Brain Res 2006, 1070:131-138

24. Resse TS, Karnovsky MJ: Fine structural localization of a blood-brainbarrier to exogenous peroxidase. J Cell Biol 1967, 34:207-217.

25. Peters A, Palay S, Webster $\mathrm{H}$ : The fine structure of the nervous system. Oxford: Oxford University Press; 1991

26. Tata DA, Anderson BJ: A new method for the investigation of capillary structure. J Neurosc Methods 2002, 113:199-206.

27. Pacheco P, González-Bernabé G, Alvarado M, Camacho M, Cuevas E, Carrillo $P$ : Brain microvasculature of the rat: Its integrative organization [abstract]. Soc Neurosci SfN 2005, 189:8.

28. Cortés-Sol A, Domínguez A, Alvarado M, Lara-García M, Camacho M, Pacheco P: Capillary distribution in magnocellular and parvocellular area of paraventricular nucleus of virgin and lactating rats [abstract]. Soc Neurosci SFN 2008, 395:15.

29. Van den Pol AN: The magnocellular and parvocellular paraventricular nucleus of the rat: intrinsic organization. J Comp Neurol 1982, 206:317-345.

30. Swanson LW, Sawchenko PE: Hypothalamic integration: organization of the paraventricular and supraoptic nuclei. Annu Rev Neurosci 1983, 6:269-324.

31. Armstrong WE: Hypothalamic supraoptic and paraventricular nuclei. In The rat nervous system. Edited by Paxinos G. Sydney: Academic Press; 1985:119-128.

32. Moos F, Richard P: Paraventricular and supraoptic bursting oxytocin cells in rat are locally regulated by oxytocin and functionally related. $J$ Physiol 1989, 408:1-18.

33. Wakerley JB: Milk ejection and its control. In Physiology of reproduction, Volume 2. 3rd edition. Edited by Knobil E, Neill JD. New York: Academic Press, Elsevier; 2006:3129-3176.

34. Newman I, Russell JA, Landgraf R: Oxytocin and vasopressin release within the supraoptic and paraventricular nuclei of pregnant, parturient and lactating rats: a microdialysis study. Neuroscience 1993, 53:65-75.

35. Jiang QB, Wakerley JB: Analysis of bursting responses of oxytocin neurons in the rat in late pregnancy, lactation and after weaning. J Physiol 1995, 486:237-248. 
36. Mena F, Pacheco P, Aguayo D, Clapp C, Grosvenor CE: A rise in intramammary pressure follows electrical stimulation of mammary nerve in anesthetized rats. Endocrinology 1978, 103:1929-1936.

37. Sutherland RC, Aizlewood ES, Wakerley JB: Changing characteristics of the milk ejection reflex during pregnancy, lactation and after weaning in the rat. J Reprod Fertil 1986, 76:123-130.

38. Paxinos $G$, Watson C: The rat brain in stereotaxic coordinates. London: Academic Press, Elsevier; 2007.

39. Ambach G, Palkovits M: Blood supply of the rat hypothalamus. II. Nucleus paraventricularis. Acta Morphol Acad Sci Hung 1974, 22:311-320.

40. Sposito NM, Gross PM: Morphometry of individual capillary beds in the hypothalamus-neurohypophysial system of rats. Brain Res 1987 403:375-379.

41. Catheline G, Touquet B, Lombard MC, Poulain DA, Theodosis DT: A study of the role of neuro-glial remodeling in the oxytocin system at lactation. Neuroscience 2006, 137:309-316.

42. Theodosis DT, Trailin A, Poulain DA: Remodeling of astrocytes, a prerequisite for synapse turnover in the adult brain? Insights from the oxytocin system of the hypothalamus. Am J Physiol Regul Integr Comp Physiol 2006, 290:1175-1182.

43. Lin SH, Miyata S, Matsunaga W, Kawarabayashi T, Nakashima T, Kiyohara T: Metabolic mapping of the brain in pregnant, parturient and lactating rats using fos immunohistochemistry. Brain Res 1998, 787:226-236.

44. Laurie GW, Leblond CP, Martin GR: Localization of type IV collagen, laminin, heparin sulfate proteoglycan, and fibronectin to the basal lamina of basement membranes. J Cell Biol 1982, 95:340-344.

45. Charron AJ, Xu W, Bacallao RL, Wandinger-Ness A: Cablin: a novel protein of the capillary basal lamina. Am J Physiol Heart Circ Physiol 1999, 277:1985-1996.

46. del Zoppo GJ, Milner R: Integrin-matrix interactions in the cerebral microvasculature. Arterioscler Thromb Vasc Biol 2006, 26:1966-1975.

47. Alberts B, Bray D, Lewis J, Raff M, Roberts K, Watson J: Molecular biology of the cell. New York: Garland Science, Taylor \& Francis Group; 2007.

48. Sanders AG, Ebert RH, Florey HW: The mechanism of capillary contraction. Q J Exp Physiol Cogn Med Sci 1940, 30:281-287.

49. Rosso L, Peteri-Brunbäck B, Poujeol P, Hussy N, Mienville JM: Vasopressininduced taurine efflux from rat pituicytes: a potential negative feedback for hormone secretion. J Physiol 2004, 554:731-742.

50. Avella M, Ducoudret O, Pisani DF, Poujeol P: Swelling-activated transport of taurine in cultured gill cells of sea bass: physiological adaptation and pavement cell plasticity. Am J Physiol Regul Integr Comp Physiol 2009, 296:1149-1160.

51. Lang F: Mechanisms and significance of cell volume regulation. J Am Coll Nutr 2007, 26:613-623.

52. Yool AJ: Aquaporins: multiple roles in the central nervous system. Neuroscientist 2007, 13:470-485

53. Freeman $L R$, Keller JN: Oxidative stress and cerebral endothelial cells: regulation of the blood-brain-barrier and antioxidant based interventions. Biochim Biophys Acta 2012, 1822:822-829.

54. Simionescu N, Simionescu M, Palade GE: Differentiated microdomains on the luminal surface of the capillary endothelium. I. Preferential distribution of anionic sites. J Cell Biol 1981, 90:605-613.

55. Tuma PL, Hubbard AL: Transcytosis: crossing cellular barriers. Physio/ Rev 2003, 83:871-932

56. Landgraf R, Neumann ID: Vasopressin and oxytocin release within the brain: a dynamic concept of multiple and variable modes of neuropeptide communication. Front Neuroendocrinol 2004, 25:150-76.

57. Parker SL, Armstrong WE, Sladek CD, Grosvenor CE, Crowley WR: Prolactin stimulated the release of oxytocin in lactating rats: evidence for a physiological role via an action at the neural lobe. Neuroendocrinology 1991, 53:503-510.

58. Vega C, Moreno-Carranza B, Zamorano V, Quintanar-Stéphano A, Méndez I, Thebault S, Martínez De La Escalera G, Clapp C: Prolactin promotes oxytocin and vasopressin release by activating neuronal nitric oxide synthase in the supraoptic and paraventricular nuclei. Am J Physiol Regul Integr Comp Physiol 2010, 299:1762-1770.

59. Ivanov KP, Kalinina MK, Levkovich Yu I: Blood flow velocity in capillaries of brain and muscles and its physiological significance. Microvasc Res 1981, 22:143-155
60. Nnodim JO: Quantitative study of the effects of denervation and castration on the levator ani muscle of the rat. Anat Rec 1999, 255:324-33

61. Alvarado M, Cuevas E, Lara-García M, Camacho M, Carrillo P, Hudson R, Pacheco P: Effect of gonadal hormones on the cross-sectional area of pubococcygeus muscle fibers in male rat. Anat Rec 2008, 291:586-92.

doi:10.1186/1471-2202-14-7

Cite this article as: Cortés-Sol et al:: Inner capillary diameter of hypothalamic paraventricular nucleus of female rat increases during lactation. BMC Neuroscience 2013 14:7.

\section{Submit your next manuscript to BioMed Central and take full advantage of:}

- Convenient online submission

- Thorough peer review

- No space constraints or color figure charges

- Immediate publication on acceptance

- Inclusion in PubMed, CAS, Scopus and Google Scholar

- Research which is freely available for redistribution 